Abstracted/indexed in Academic Search Complete, Agroforestry Abstracts, Asia Journals Online, Bangladesh Journals Online, Biological Abstracts, BIOSIS Previews, CAB Abstracts, Current Abstracts, Directory of Open Access Journals, EMBASE/Excerpta Medica, Google Scholar, HINARI (WHO), International Pharmaceutical Abstracts, Open J-gate, Science Citation Index Expanded, SCOPUS and Social Sciences Citation Index ISSN: 1991-0088; DOI: 10.3329/bjp.v9i4.20879

\title{
Pharmacological basis for the medicinal use of Rhus coriaria in hyperactive gut disorders
}

\author{
Khalid Hussain Janbaz², Arham Shabbir'1,2,3, Malik Hassan Mehmood' and Anwarul \\ Hassan Gilani ${ }^{1,4}$
}

${ }^{1}$ Natural Product Research Division, Department of Biological and Biomedical Sciences, The Aga Khan University Medical College, Karachi 74800, Pakistan; ${ }^{2}$ Faculty of Pharmacy, Bahauddin Zakariya University, Multan 60800, Pakistan; ${ }^{3}$ Department of Pharmacy, COMSATS Institute of Information Technology, Abbottabad 22060, Pakistan; ${ }^{4}$ Department of Pharmacy, College of Health Sciences, Mekelle University, Mekelle, Ethiopia.

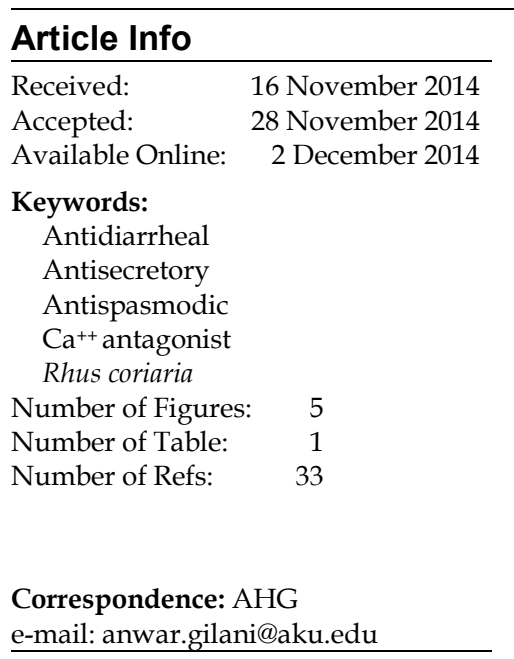

\begin{abstract}
This study was aimed at providing the pharmacological basis for the medicinal use of Rhus coriaria in diarrhea. In mice, the crude of $R$. coriaria demonstrated antisecretory and antidiarrheal effects against castor oil-induced fluid accumulation and diarrhea at at 100 and $300 \mathrm{mg} / \mathrm{kg}$, respectively, and was found safe up to tested dose of $5 \mathrm{~g} / \mathrm{kg}$. In isolated rabbit jejunum, $R$. coriaria exhibited concentration-dependent $(0.01-3.0 \mathrm{mg} / \mathrm{mL})$ relaxation of spontaneous and high $\mathrm{K}^{+}(80 \mathrm{mM})$-induced contractions, similar to verapamil. The $\mathrm{Ca}^{++}$antagonist activity was confirmed when pretreatment of $R$. coriaria shifted $\mathrm{Ca}^{++}$concentration-response curves to the right with suppression of maximal response, similar to verapamil. $R$. coriaria also suppressed the high $\mathrm{K}^{+}$ -evoked transient contractile peaks similar to the effect of cyclopiazonic acid and verapamil. This study indicates that $R$. coriaria possesses antisecretory, antidiarrheal and antispasmodic properties mediated possibly through $\mathrm{Ca}^{++}$ antagonist pathway, thus providing evidence to its medicinal use in diarrhea and abdominal spasm.
\end{abstract}

\begin{abstract}
Introduction
Rhus coriaria Linn. (family: Anacardiacea), commonly known as Sumac, is a perennial bushy shrub of about 3 meter height, growing wild in Mediterranean areas, North Africa, Middle East, Iran and Afghanistan (Özcan and Haciseferogullari, 2004). The leaves being rich in tannins were used in dying and tanning of leather. The red colored fruits are used as condiment and are major ingredient of Zatar, a popular Arabic spice mixture. The fruits have also been employed traditionally to manage diarrhea, dysentery, sore throat and toothaches (Usmanghani et al., 1997; Lev and Amar, 2002; Shabbir, 2012).
\end{abstract}

Phytochemical investigations on $R$. coriaria reported presence of ellagic acid, gallic acid, tannic acid, avicularin, myricetin, myricitrin, isoquercetin, quercetin and quercetrin as plant constituents (Duke, 2003; Mehrdad et al., 2009; Shabbir, 2012).

Studies on $R$. coriaria documented antibacterial (Abbas and Halkman, 2004; Shanab et al., 2005), hypoglycemic (Giancarlo et al., 2006), antioxidant (Özcan, 2003; Candan and Sokmen, 2004), xanthine oxidase inhibitor (Candan, 2003), antimigratory (Zargham and Zargham, 2008), and DNA protective properties (Chakraborty et al., 2009), while its other actions have also been summarized in a recent review (Shabbir, 2012). The present study was undertaken in an attempt to validate traditional antidiarrheal use of $R$. coriaria fruits. 


\section{Materials and Methods}

Plant material and preparation of the crude extract: The dried fruits of $R$. coriaria were purchased from a local herbal store in Multan and authenticated by a taxonomist. A specimen, voucher \# RC-F-06-08-100, was preserved in the herbarium of the Natural Product Research Division, Department of Biological and Biomedical Sciences, the Aga Khan University, Karachi. The plant material was rendered free of adulterants and was grinded into coarse powder. The powdered material $(1 \mathrm{~kg})$ was soaked in $80 \%$ methanol for 1 week with twice a day shaking. The material was passed through muslin cloth to remove vegetative debris and the obtained fluid was subsequently filtered through Whatman No. 1 filter paper. The filtrate was evaporated under reduced pressure at $35^{\circ} \mathrm{C}$ on a rotary evaporator (Buchii model RE-111, Switzerland) to a thick paste (Shah et al., 2011), which was subsequently lyophilized to dry powder on a freeze dryer (Alpha 1-4 LD, Christ, Germany) with approximate yield of $6 \%$. The crude methanolic extract of $R$. coriaria (RCE) was found soluble in distilled water/saline for in vivo and in vitro experiments and all dilutions were made fresh on the day of experiment.

Chemicals: Acetylcholine chloride, atropine sulphate, loperamide, potassium chloride verapamil hydrochloride, calcium chloride, glucose, magnesium chloride, sodium chloride, ethylenediamine-tetraacetic acid (EDTA), aluminum chloride, ammonium hydroxide, dragendorff's reagent and ferric chloride were purchased from Sigma-Aldrich Chemicals Company, St Louis, MO, USA. Sodium bicarbonate, sodium dihydrogen phosphate, methanol, benzene, chloroform, hydrochloric acid and petroleum ether were obtained from E. Merck KGa (Darmstadt, Germany). The castor oil was purchased from Karachi Chemical Industries (Pvt.) Ltd., Karachi (Pakistan).All the chemicals used were of analytical reagent grade and dissolved in distilled water/saline for in vivo and in vitro experiments.

Animals: The adult (male or female) BALB/c mice (20$25 \mathrm{~g}$ ) and local breed rabbit (1-1.5 kg) were housed at the Animal House of The Aga Khan University, Karachi, in their respective cages lined with sawdust (renewed after every 48 hours), maintained at $23-25^{\circ} \mathrm{C}$, humidity $60 \% \pm 4 \%, 12 / 12$ hours light and dark cycles. Animals were provided ad libitum with tap water and standard diet consisting of $(\mathrm{g} / \mathrm{kg})$ : flour (380), fiber (380), molasses (12), sodium chloride (5.80, nutrivet L (2.5), potassium metabisulphate (1.2), vegetable oil (38), fish meal (170) and powdered milk (150). The animals were subjected to 12-16 hours starvation prior to the day of experiment but had free access to water. Experiments performed were complied with the rulings of the Institute of Laboratory Animal Resources, Commission on Life Sciences, National Research Council, 1996
(National Research Council, 1996).

Intestinal fluid accumulation assay: By following an earlier method (Mehmood and Gilani, 2010), overnight fasted mice (weighing 20-25 g, $\mathrm{n}=30$ ) of both sexes were housed in cages in five equally divided groups $(n=6)$. The first two groups received saline in a solubilizing vehicle $(10 \mathrm{~mL} / \mathrm{kg}$, p.o.) and acted as negative controls. The animals in group three was administered verapamil $(100 \mathrm{mg} / \mathrm{kg})$ intraperitoneally using a detachable U-100 insulin syringe with a $25 \mathrm{G} \times 1$ " $(0.50$ $\times 25 \mathrm{~mm}$ ) needle, as positive control. The fourth and fifth groups were treated with increasing doses of the plant extract (100 and $300 \mathrm{mg} / \mathrm{kg}$, i.p). One hour after the treatment, each animal received castor oil $(10 \mathrm{~mL} /$ $\mathrm{kg}$ ) orally, except the animals in group one. All the animals were sacrificed $30 \mathrm{~min}$ later by cervical dislocation and the intestine was dissected out carefully, not allowing any intestinal fluid to leak out, and weighed. The results were expressed as $(\mathrm{Pi} / \mathrm{Pm})$ $\times 1000$ whereas, $P i$ is the weight of the intestine and $P m$ is the weight (in g) of the animal.

Antidiarrheal activity: The antidiarrheal activity of RCE was assessed by slight modifications of a previously described method (Shah et al., 2011A). Twenty mice (20 $-25 \mathrm{~g}$ ) were divided into 4 groups and each group was containing 5 animals. The animals were housed in individual cages and were subjected to 12-16 hours fasting prior to start of experiment. The group $1^{\text {st }}$ animals were taken as negative control to which normal saline $(10 \mathrm{~mL} / \mathrm{kg})$ was administered orally and followed after 1 hour by an oral dose of castor oil (10 $\mathrm{mL} / \mathrm{kg}$ ). The group $2^{\text {nd }}$ animals were regarded as positive control and treated similar to group $1^{\text {st }}$ animals except oral dose of loperamide $(10 \mathrm{mg} / \mathrm{kg})$ was substituted for normal saline. The group $3^{\text {rd }}$ and $4^{\text {th }}$ animals were treated similar to group $1^{\text {st }}$ except crude extract at respective oral doses of 100 and $300 \mathrm{mg} / \mathrm{kg}$ was substituted for normal saline. After 4 hours the mouse cages were individually inspected for the presence of diarrheal wet feces and percentage decrease in the wet feces output as compared to the castor oil treated group was used to assess antidiarrheal effect. While counting the number of wet and dry feces, the dry feces was counted one in number when its size was found in between the range of an average size of a dry feces $(1.3 \pm 0.6 \mathrm{~cm}$, width $0.4 \pm 0.3 \mathrm{~cm}, \mathrm{n}=20)$. Similarly to count wet feces, the average size was considered as, the length $2 \pm 1.4 \mathrm{~cm}$ and width $1 \pm 0.7 \mathrm{~cm}, \mathrm{n}=20$, with the exception of making decisions on the basis of our observational experience when there are discrepancies like, an irregular liquid left circle with the semisolid fecal mass in the center or merging of two or three wet feces with a large covered area on white blotting paper.

Spasmolytic activity: The antispasmodic activity of the crude extract was investigated on isolated rabbit jejunum preparations by using previously described 
methods (Khan et al., 2012; Shah et al., 2014). The male/female rabbits $(1-1.5 \mathrm{~kg})$ of local breed were subjected to 12-16 hours starvation and sacrificed subse -quent to cervical dislocation. The jejunum was dissected out and placed in Tyrode's solution aerated with carbogen $\left(95 \% \mathrm{O}_{2}+5 \% \mathrm{CO}_{2}\right)$ to remove the mesenteries. The jejunum was cut into $2 \mathrm{~cm}$ long tissue segments which were mounted in $10 \mathrm{~mL}$ tissue organ baths filled with Tyrode's solution maintained at $37^{\circ} \mathrm{C}$ and continuously aerated with carbogen. A preload of $1 \mathrm{~g}$ was applied to each tissue and was allowed to equilibrate for $30 \mathrm{~min}$ prior to the addition of any test material. The tissues were stabilized by repeated exposure to sub-maximal concentration of acetylcholine (ACh; $0.3 \mu \mathrm{M}$ ). The preparations were presumed stable when three successive responses to acetylcholine were found to be identical. The isolated rabbit jejunum preparations exhibit spontaneous rhythmic contractions on which spasmolytic activity was tested directly without using any agonist (Mehmood et al., 2011). The crude extract was added to the tissue baths in cumulative manner and the obtained response was expressed as the percent change of spontaneous contractions in rabbit jejunum recorded prior to the exposure of the test material. The intestinal contractions were recorded via isotonic transducer 50-6360 (Harvard Apparatus, Holliston, MA, USA) attached to PowerLab (model: ML -845), data acquisition system (AD Instruments; Sydney, Australia).

The crude extract was subjected to further investigations to elucidate possible mechanism of its observed antispasmodic action through influence on high $\mathrm{K}^{+}(80$ $\mathrm{mM}$ )-induced contractions. The isolated tissue preparations on exposure to high $\mathrm{K}^{+}$produce a sustained contraction through opening of voltage dependent $\mathrm{Ca}^{++}$ channels (VDCs) on which extract solution was applied in a cumulative manner to obtain concentration-dependent inhibitory responses (Van Rossum, 1963). The observed relaxant effect of RCE on high $\mathrm{K}^{+}$-induced contraction on isolated rabbit jejunum preparations was quantified as percentage of the controlled contractile response and was speculated to be mediated through blockade of VDCs.

To confirm $\mathrm{Ca}^{++}$channel blocking effect, isolated rabbit jejunum preparations were allowed to stabilize in normal Tyrode's solution whose composition was (mM): $\mathrm{KCl}$ (2.68), $\mathrm{NaCl}$ (136.9), $\mathrm{MgCl}_{2}$ (1.05), $\mathrm{NaHCO}_{3}$ (11.90), $\mathrm{NaH}_{2} \mathrm{PO}_{4}$ (0.42), $\mathrm{CaCl}_{2}$ (1.8) and glucose (5.55), which was subsequently replaced with $\mathrm{Ca}^{++}$-free Tyrode's solution containing EDTA $(0.1 \mathrm{mM})$ for $30 \mathrm{~min}$ in order to remove $\mathrm{Ca}^{++}$from the tissue. The solution was further replaced with $\mathrm{K}^{+}$-rich and $\mathrm{Ca}^{++}$-free Tyrode's solution, having the following composition $(\mathrm{mM}): \mathrm{KCl}$ (50), $\mathrm{NaCl}$ (91.04), $\mathrm{MgCl}_{2}$ (1.05), $\mathrm{NaHCO}_{3}$ (11.90), $\mathrm{NaH}_{2} \mathrm{PO}_{4}(0.42)$, glucose (5.55) and EDTA (0.1). Following an incubation period of $30 \mathrm{~min}, \mathrm{Ca}^{++}$was added in cumulative manner to obtain control calcium concen- tration-response curves (CRCs). The experiment was repeated until the successive control CRCs of $\mathrm{Ca}^{++}$were found to be super-imposable (usually after two cycles). The tissues were washed and allowed to be equilibrated in the presence of RCE for 1 hour followed by the construction of CRCs of $\mathrm{Ca}^{++}$in the presence of various concentrations of RCE and standard drug verapamil and compared with the control curve.

Smooth muscle contractions are produced either by the extracellular $\mathrm{Ca}^{++}$influx or the intracellular $\mathrm{Ca}^{++}$release from sarcoplasmic reticulum (SR), hence the effect of the extract was observed on intracellular $\mathrm{Ca}^{++}$release from SR. High $\mathrm{K}^{+}$-induced contractions were recorded in the absence and presence of RCE, cyclopiazonic acid, a specific inhibitor of $\mathrm{Ca}^{++}$ATPase in smooth muscle SR (Seidler et al., 1989) and verapamil possessing inhibitory influence on both the extracellular $\mathrm{Ca}^{++}$influx via VDCs and the intracellular $\mathrm{Ca}^{++}$release form internal stores (Bolton, 1979). As, the high $\mathrm{K}^{+}$is a known spasmogen to produce contraction by extracellular $\mathrm{Ca}^{++}$ influx through VDCs and intracellular $\mathrm{Ca}^{++}$release from SR (Brading, 1981). Thus, a substance, similar to cyclopiazonic acid, inhibiting partially the high $\mathrm{K}^{+}-$ induced contractions at low doses can be speculated to affect the release of $\mathrm{Ca}^{++}$from SR.

Acute toxicity test: Twenty four (male/female) BALB/c mice $(20-25 \mathrm{~g})$ were divided into 4 groups and each group was containing 6 animals. The group $1^{\text {st }}, 2^{\text {nd }}$ and $3^{\text {rd }}$ of mice served as test groups and were treated orally with the respective crude extract dose of 1,3 and $5 \mathrm{~g} / \mathrm{kg}$. The group $4^{\text {th }}$ animals served as negative control and were treated with saline $(10 \mathrm{~mL} / \mathrm{kg})$. The animals were deprived of food 12 hours prior to the test, while water remained freely available. The animals had been under strict observation for 8 hours for possible behavioral change and 24 hours monitoring for possible mortality.

Statistical analysis: The data was expressed as mean \pm standard error of the mean (s.e.m; $n=$ number of experiments) and the median effective concentrations (EC 50 values) with $95 \%$ confidence intervals (CI). Oneway ANOVA followed by Dunnett's test was used for antidiarrheal activity experiments, while two-way ANOVA followed by Bonferroni's post-test correction was used for comparison of concentration-response curves (CRCs) with the control and $p<0.05$ was considered significantly different. The CRCs were analyzed by non-linear regression using GraphPAD program (GraphPAD, San Diego, California, USA).

\section{Results}

In enteropooling assay, castor oil exhibited a substantial increase of fluid accumulation in mice with $(\mathrm{Pi} / \mathrm{Pm}) \times$ 1,000 value of $152 \pm 7.0$, while saline as a negative control, exhibited $104 \pm 5.1(\mathrm{p}<0.001)$. Crude excract of 
R. coriaria produced significant $(p<0.001)$ reduction in castor oil-induced fluid accumulation at 100 and 300 $\mathrm{mg} / \mathrm{kg}$ with $(\mathrm{Pi} / \mathrm{Pm}) \times 1,000$ values of $90 \pm 2.9$ and $69 \pm$ 5.2 , respectively, similar to verapamil $(65 \pm 3.2)$ at a dose of $100 \mathrm{mg} / \mathrm{kg}$. All $(\mathrm{Pi} / \mathrm{Pm}) \times 1,000$ values are expressed as mean \pm s.e.m, $n=6$ (Figure 1).

When tested in mice against castor oil-induced diarrhea, the plant extract at a dose of 100 and $300 \mathrm{mg} / \mathrm{kg}$ reduced the total number of wet feces to $4.33 \pm 1.51$ and $2.75 \pm 2.64$, (mean \pm SEM, $n=6)$, respectively when compared with saline $(8.75 \pm 2.32, n=6)$, while loperamide administration (a positive control) reduced the number of wet feces to $1.17 \pm 1.47$, the detail has been given in Table I.

The crude extract caused inhibition of spontaneous and high $\mathrm{K}^{+}(80 \mathrm{mM})$-induced spastic contractions in isolated rabbit jejunum preparations with respective $\mathrm{EC}_{50}$ values of $0.35 \mathrm{mg} / \mathrm{mL}(0.26-0.46 \mathrm{mg} / \mathrm{mL} ; n=5)$ and $0.04 \mathrm{mg} / \mathrm{mL}(0.03-0.08 \mathrm{mg} / \mathrm{mL} ; n=4)$ (Figure 2 and 3A). Verapamil (standard $\mathrm{Ca}^{++}$channel blocker) also relaxed the spontaneous and high $\mathrm{K}^{+}(80 \mathrm{mM})$ induced contractions with $\mathrm{EC}_{50}$ values of $0.78 \mathrm{mg} / \mathrm{mL}$ $(0.52-1.23 \mathrm{mg} / \mathrm{mL} ; n=4)$ and $0.08 \mathrm{mg} / \mathrm{mL}(0.04-0.16$ $\mathrm{mg} / \mathrm{mL} ; n=5)$ (Figure 2 and 3B).

The $\mathrm{Ca}^{++}$channel blocking activity was confirmed further when crude extract treatment of the isolated rabbit jejunum preparations resulted in rightward shift in the CRCs for $\mathrm{Ca}^{++}$with suppression $(\mathrm{p}<0.001)$ of the maximal response $(100 \%)$ to a level of $63.7 \pm 7.01 \%$ $(n=7)$ and $38.5 \pm 3.5 \%(n=6)$ at respective tissue bath concentration of 0.01 and $0.03 \mathrm{mg} / \mathrm{mL}$ (Figure 4A). Verapamil also produced a rightward shift in the CRCs of $\mathrm{Ca}^{++}$and attenuated $(\mathrm{p}<0.001)$ the maximal response

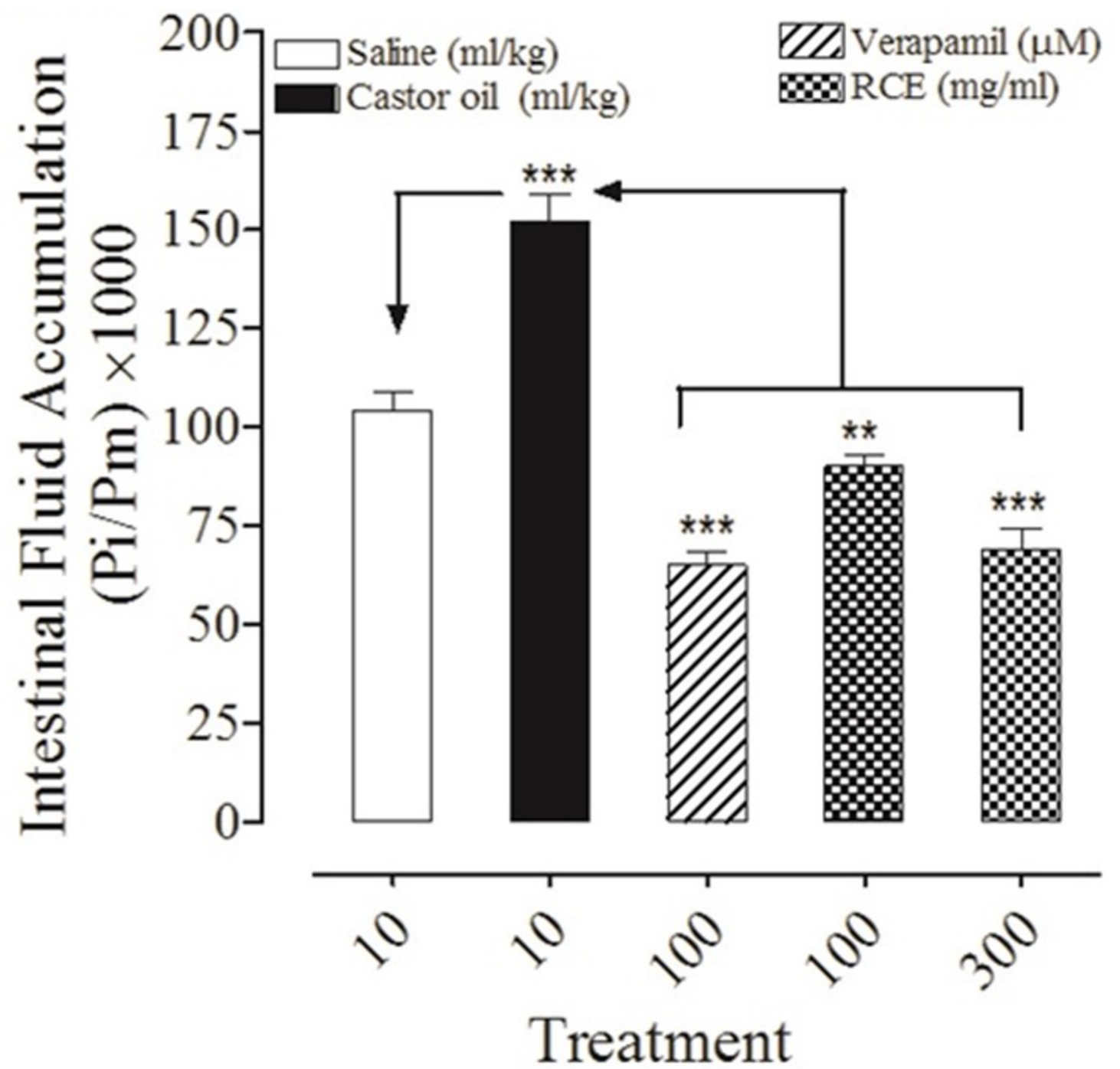

Figure 1: The dose-dependent inhibitory effect of the crude extract of Rhus coriaria (RCE) on castor oil-induced fluid accumulation in the small intestine of mice. Intestinal fluid accumulation is expressed as $P i / P m \times 1000$ whereas $P i$ is the weight of the small intestine and $P m$ is the weight (in g) of the mouse. The values are mean \pm s.e.m., $\mathrm{n}=6$. ${ }^{* *} p<0.01$ and ${ }^{* * *} p<0.001$ (Unpaired $t$-test or One -way ANOVA followed by Dunnett's test). 
Table I. The protective effect of the crude extract of Rhus coriaria (RCE) on castor oil-induced diarrhea in mice.

\begin{tabular}{|l|c|c|c|}
\hline Treatment & $\begin{array}{c}\text { Mean fecal } \\
\text { output in } 4 \text { hours }\end{array}$ & $\begin{array}{c}\text { Mean No. of } \\
\text { Wet feces in } 4 \text { hours }\end{array}$ & Protection \\
\hline Saline $(10 \mathrm{~mL} / \mathrm{kg})$ plus castor oil $(10 \mathrm{~mL} / \mathrm{kg})$ & $10.0 \pm 2.2$ & $8.8 \pm 2.3$ & 12.5 \\
\hline Loperamide $(10)$ plus castor oil $(10 \mathrm{~mL} / \mathrm{kg})$ & $3.5 \pm 2.6^{\mathrm{a}}$ & $1.2 \pm 1.5^{\mathrm{b}}$ & 66.5 \\
\hline $\mathrm{RCE}(100 \mathrm{mg} / \mathrm{kg})$ plus castor oil $(10 \mathrm{~mL} / \mathrm{kg})$ & $8.8 \pm 2.7$ & $4.3 \pm 1.5^{\mathrm{a}}$ & 50.5 \\
\hline RCE $(300 \mathrm{mg} / \mathrm{kg})$ plus castor oil $(10 \mathrm{~mL} / \mathrm{kg})$ & $6.4 \pm 4.3$ & $2.8 \pm 2.6^{\mathrm{b}}$ & 57.1 \\
\hline $\begin{array}{l}\text { Each group contained } 6 \text { animals. }{ }^{\mathrm{p}} \mathrm{p}<0.01 \mathrm{and}{ }^{\mathrm{b}} \mathrm{p}<0.001 \text { compared with saline + castor oil treated group }(\text { One-way ANOVA followed by Dunnett's } \\
\text { test) }\end{array}$ &
\end{tabular}

\section{Control}
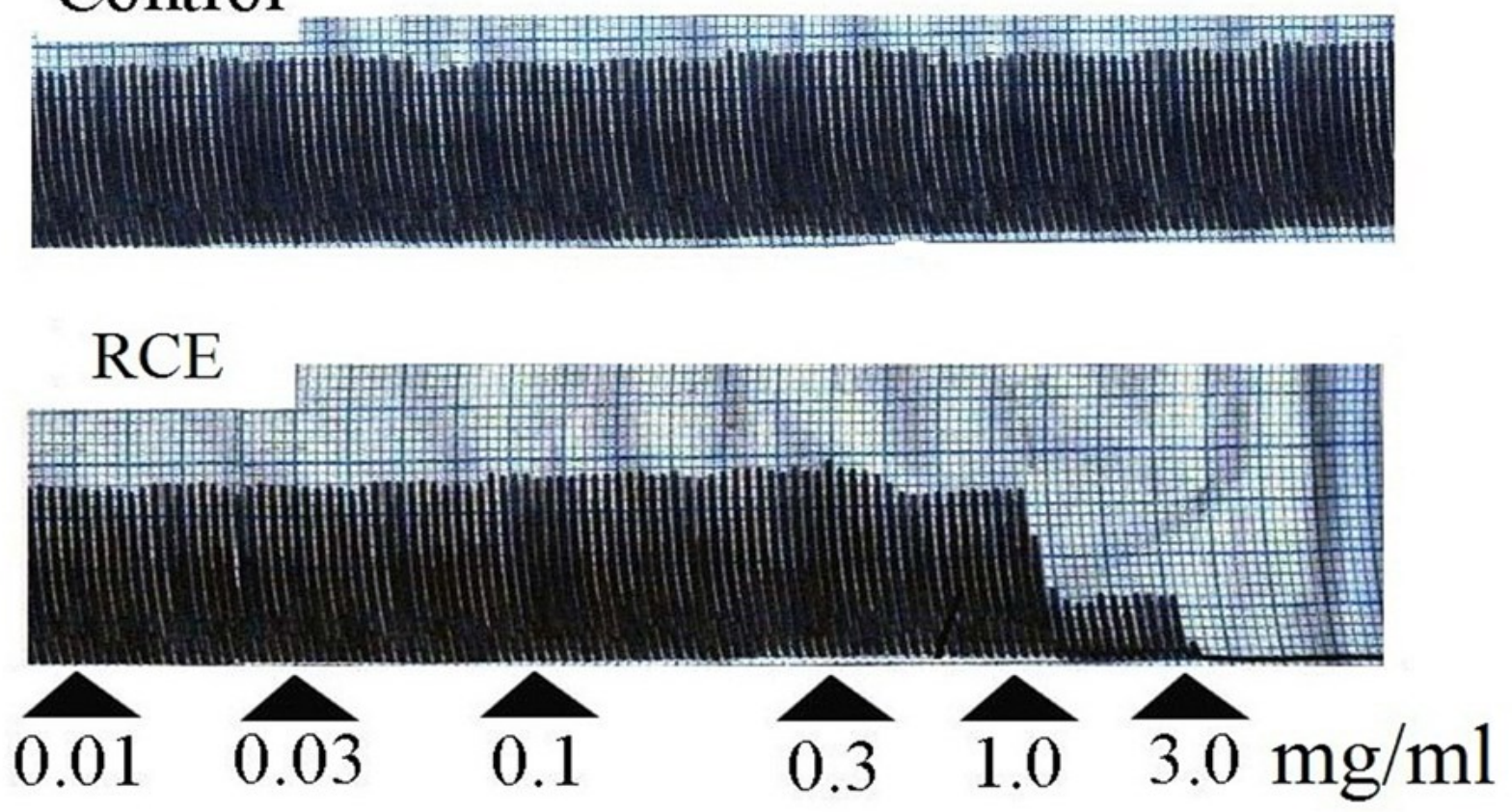

\section{Verapamil}

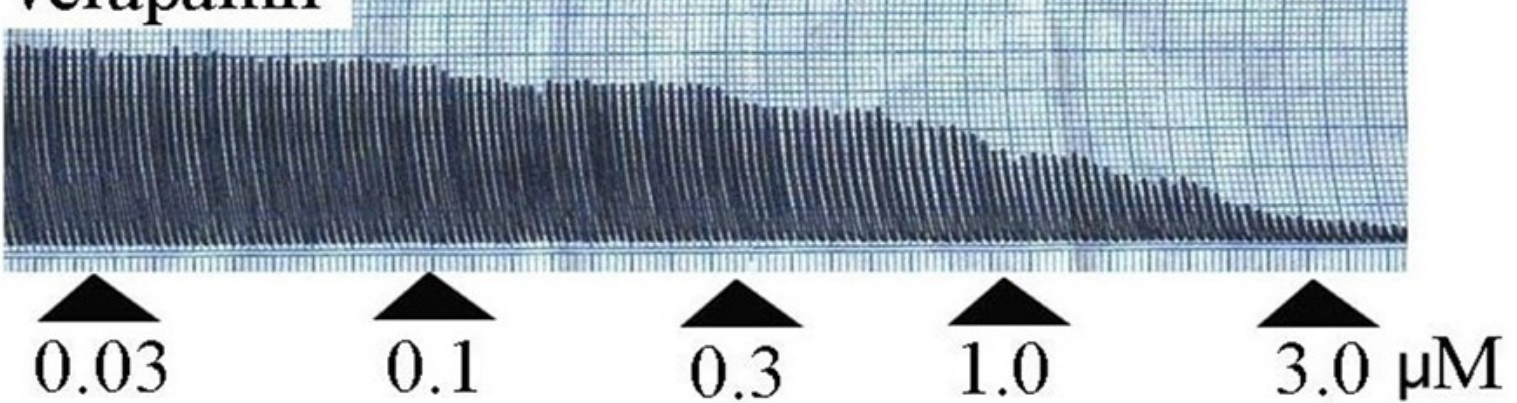

Figure 2: Tracing showing the relaxant effects of the crude extract of Rhus coriaria (RCE) and verapamil on spontaneous contractions of isolated rabbit jejunum preparations

to $62 \pm 7.8 \%(n=5)$ and $22.2 \pm 7.7 \%(n=4)$ at respective tissue bath concentrations of 0.01 and $0.03 \mu \mathrm{M}$ (Figure 4B).

Pretreated rabbit jejunal preparations with RCE caused a partial inhibitory influence on high $\mathrm{K}^{+}$evoked spastic contractions at 0.03 and $0.1 \mathrm{mg} / \mathrm{mL}$ with respective values of $78.5 \pm 2.7 \%(n=4)$ and $57.3 \pm 2.6 \%$ $(\mathrm{n}=5)$ of the control high $\mathrm{K}^{+}$-induced contractions taken as $100 \%$, similar to the effect of cyclopiazonic acid at 10 $\mu \mathrm{M}(53.7 \pm 2.8 \%, \mathrm{n}=6)$ and verapamil at $0.03 \mu \mathrm{M}(70.3 \pm$ $2.1 \%, n=4)$ and $0.1 \mu \mathrm{M}(45.0 \pm 2.2 \%, \mathrm{n}=5)$ (Figure 5).

Acute toxicity test: The RCE was found safe and did not exert any harmful effect in mice up to oral doses of 1,3 and $5 \mathrm{~g} / \mathrm{kg}$. 
A

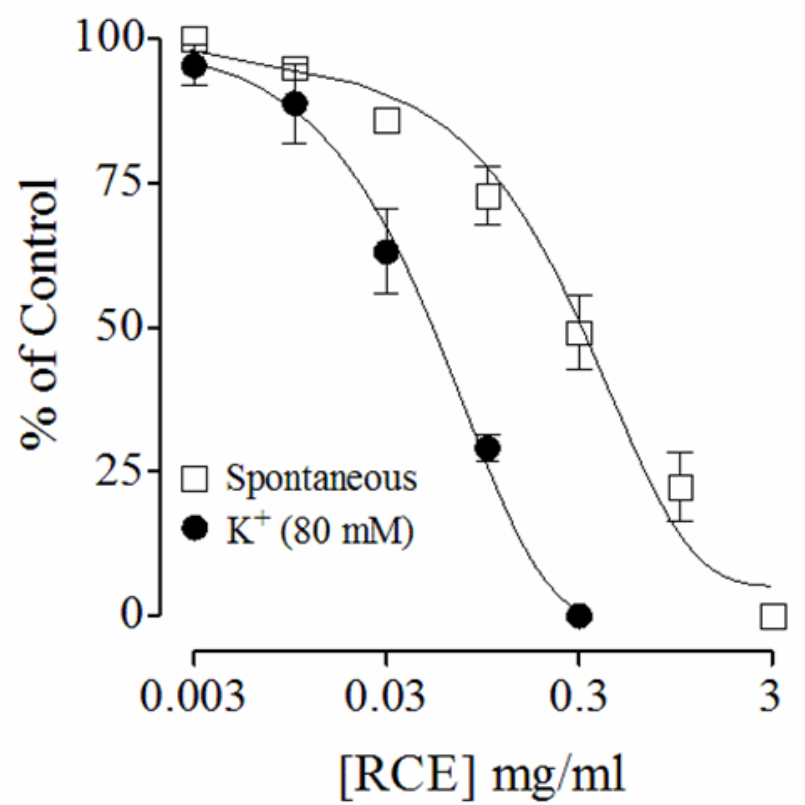

B

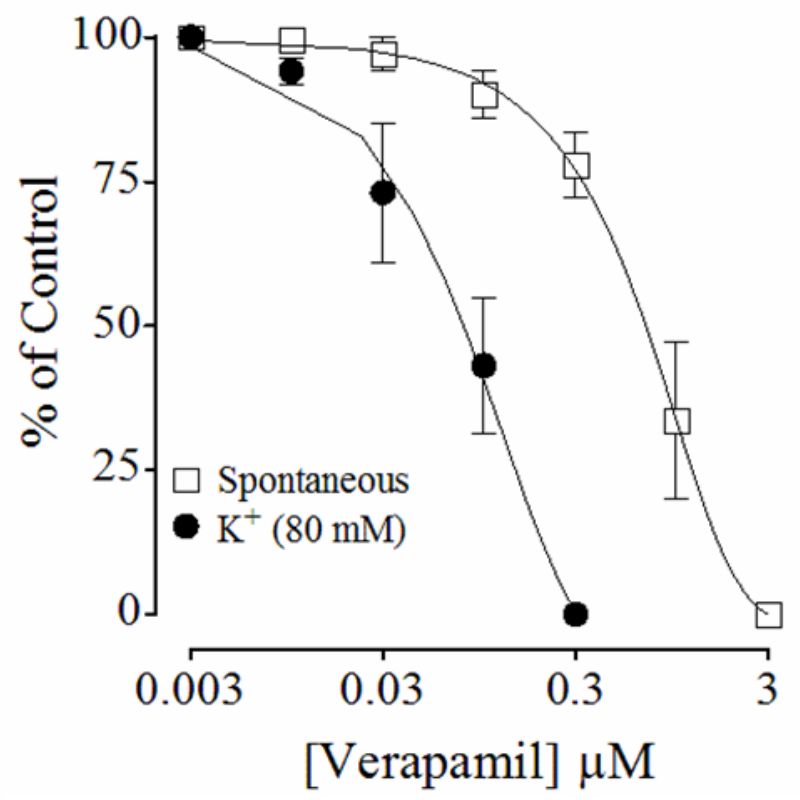

Figure 3: The spasmolytic effects of (A) the crude extract of Rhus coriaria (RCE) and (B) verapamil on spontaneous and high $\mathrm{K}^{+}(80 \mathrm{mM})$-induced contractions in isolated rabbit jejunum preparations. Values shown represent mean \pm s.e.m of $4-5$ determinations
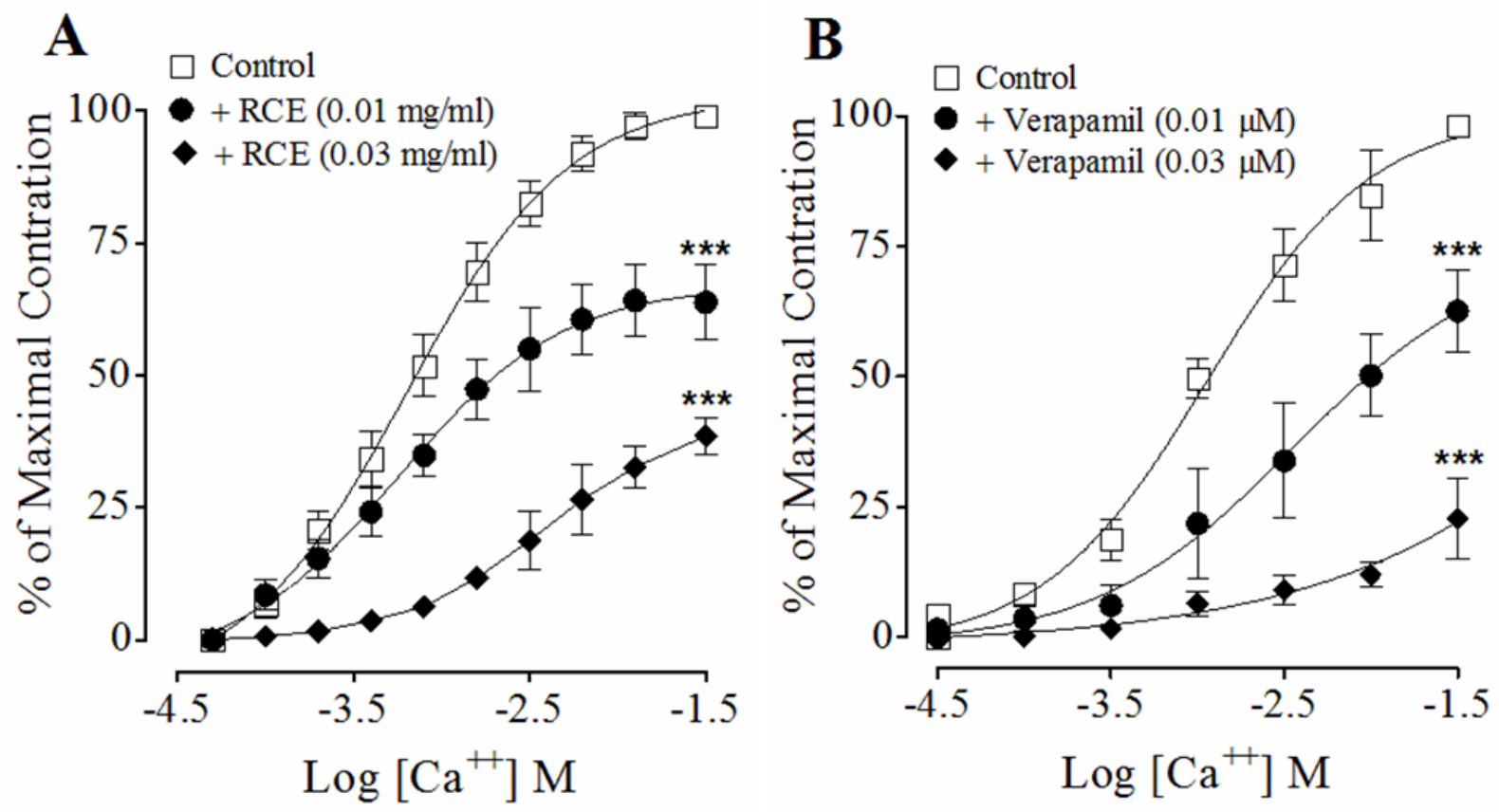

Figure 4: The concentration response curves of $\mathrm{Ca}^{++}$in the absence and presence of (A) the crude extract of Rhus coriaria (RCE) and (B) verapamil in isolated rabbit jejunum preparations. Values shown represent mean \pm s.e.m of 4-7 determinations. ${ }^{* * *} p<0.001$ vs. control (Two-way ANOVA, followed by Bonferroni's post-test correction)

\section{Discussion}

The $R$. coriaria has been used to manage diarrhea and similar other hyperactive gut disorders in the traditional system of medicines (Usmanghani et al.,
1997). The crude extract $R$. coriaria of was found to have beneficial effect on intestinal fluid contents and diarrhea as demonstrated by the observed protective effect against castor oil-induced fluid accumulation and diarrhea in mice. The castor oil-induced intestinal 


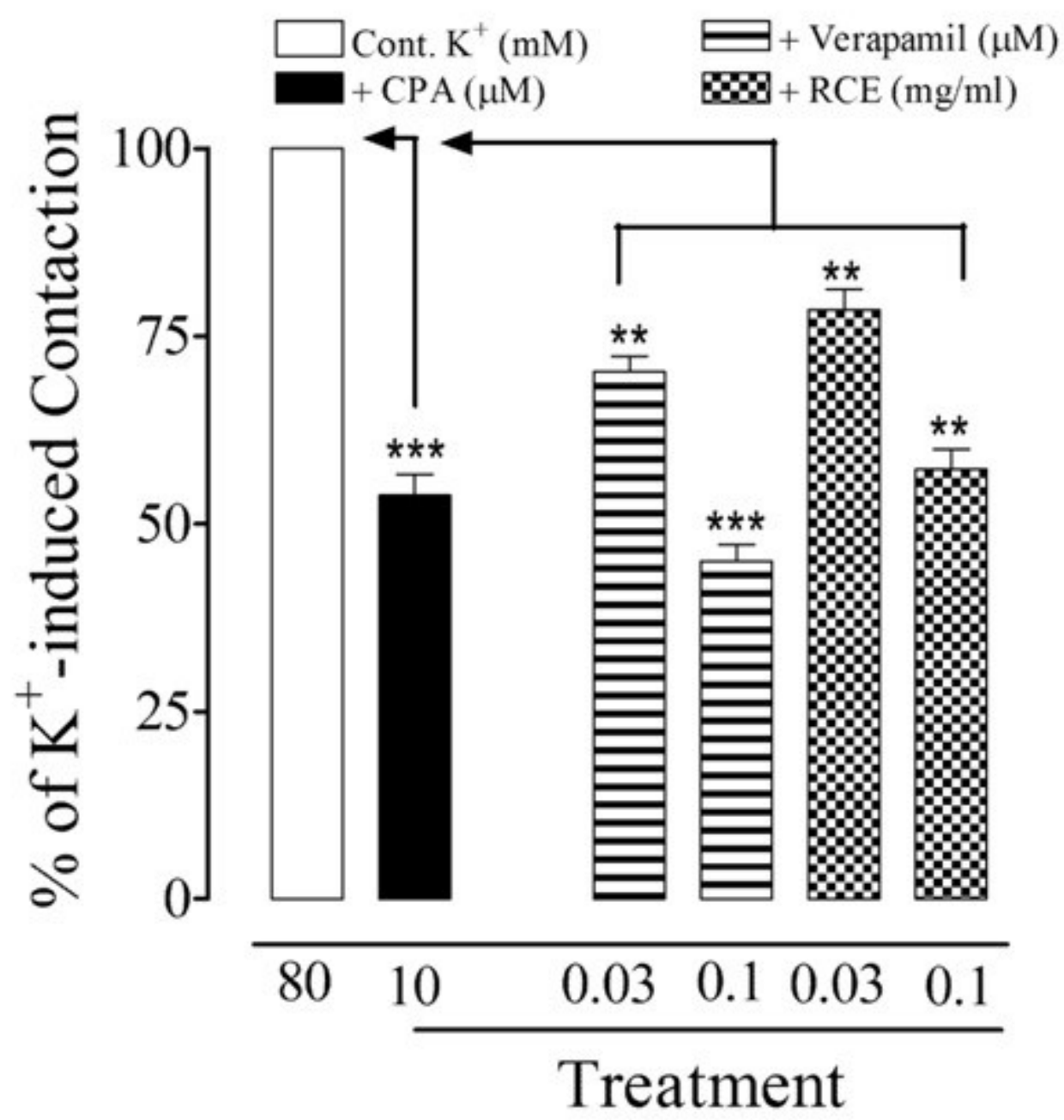

Figure 5: Bar charts showing the inhibitory effects of (A) cyclopiazonic acid (CPA), (B) verapamil and (C) the crude extract of Rhus coriaria (RCE) and on $\mathrm{K}^{+}(80 \mathrm{mM})$-induced contractions in isolated rabbit jejunum preparations. Values shown are mean \pm s.e.m, $\mathrm{n}=5-6$; ${ }^{* *} p<0.01$ and ${ }^{* * *} p<0.001$ (Unpaired $t$-test or One-way ANOVA followed by Dunnett's test)

fluid accumulation or diarrhea is an outcome of the stimulant action of ricinoleic acid liberated during hydrolysis (Iwao and Terada, 1962), which influence electrolytes and water transport and hence produce violent contractions in the transverse and distal colon (Croci et al., 1997), hence, a substance capable to inhibit castor oil-induced intestinal fluid accumulation or diarrhea would be able to demonstrate antidiarrheal effect.

To explore the possible mode of action, the spasmolytic potential of the extract was evaluated on spontaneously contracting isolated rabbit jejunum preparations (Mehmood et al., 2011; Janbaz et al., 2013; Khan et al., 2013). The increased free cytoplasmic $\mathrm{Ca}^{++}$activates the contractile elements in smooth muscle preparations, including rabbit jejunum (Karaki and Wiess, 1983). The intracellular free $\mathrm{Ca}^{++}$ concentration is likely to be raised either rapid influx through VDCs or released from intracellular $\mathrm{Ca}^{++}$ storage sites located in sarcoplasmic reticulum. The spontaneous movements in the intestine are mediated through periodic depolarization and repolarization and the action potential appears due to rapid influx of $\mathrm{Ca}^{++}$via VDCs at the climax of depolarization (Farre et al., 1991). The RCE exerted inhibitory effect on spontaneous movements in isolated rabbit jejunum preparations is likely to be mediated by interference either with in $\mathrm{Ca}^{++}$influx through VDCs or $\mathrm{Ca}^{++}$released from sarcoplasmic reticulum. The RCE exerted a concentration-dependent inhibitory response on application to high $\mathrm{K}^{+}$-induced spastic contractions. The exposure to high $\mathrm{K}^{+}(>30 \mathrm{mM})$ allows rapid influx of extracellular $\mathrm{Ca}^{++}$and contraction of smooth muscle is achieved through opening of VDCs (Reynolds et al., 1984). The observed RCE inhibition of high $\mathrm{K}^{+}$-induced contraction is likely to be mediated through inhibition of $\mathrm{Ca}^{++}$influx.

The crude extract caused a rightward shift in the $\mathrm{Ca}^{++}$ 
CRCs with suppression of the maximal response, similar to verapamil, a standard $\mathrm{Ca}^{++}$channel blocker (Bolton, 1979), strongly suggests the presence of $\mathrm{Ca}^{++}$ antagonist(s) among the plant constituents. More-over, the opioid agonists are also known for their inhibitory influence on high $\mathrm{K}^{+}$-induced contractions (Mehmood and Gilani, 2010), hence, there is a possi-bility for the involvement of opioid receptor mediated responses in the relaxant effect of the plant extract, though further investigations are needed to state with confidence. Thus, the observed $\mathrm{Ca}^{++}$antagonist effect on the part of plant extract may provide a scientific basis for the vernacular use of plant in diarrhea and abdominal spasm. The $\mathrm{Ca}^{++}$antagonists are already known to be effective in the management of gut motility disorders, such as diarrhea and abdominal cramps (Brading, 1981).

On the basis of determined $\mathrm{Ca}^{++}$antagonist-like activity of the plant extract, it was further tested for its effect on $\mathrm{Ca}^{++}$release from intracellular stores. RCE inhibited the transient contractile peak of high $\mathrm{K}^{+}$-evoked contractions, obtained via release of $\mathrm{Ca}^{++}$form intracellular stores, similar to the effect of cyclopiazonic acid (Seidler et al., 1989) and verapamil (Farre et al., 1991), which are also known for their inhibitory influence on $\mathrm{Ca}^{++}$ ATPase in smooth muscle SR, indicating an inhibitory property of RCE on $\mathrm{Ca}^{++}$release from SR. In addition, the plant materials are known to possess antibacterial activity (Abbas and Halkman, 2004) which could be an additional benefit for the management of infectious diarrhea.

The presence of $\mathrm{Ca}^{++}$antagonist-like constituent in $R$. coriaria besides being one of the possible antidiarrheal elements is well known for its antihypertensive activity (Hoffman, 2006). Hence, in case of hypertensive patient suffering from diarrhea, the administration of Rhus coriaria could be beneficial, while in normotensive patient with diarrhea, its intake might be harmful, particularly if it is well absorbed into systemic circulation. However, the fact that the plant has not been traditionally used in cardiovascular disorders (Shabbir, 2012), it is likely that either the plant has poor absorption or it contains some additional vasoconstrictor constituents, thus neutralizing the vasodilator effect due to the presence of $\mathrm{Ca}^{++}$antagonist-like constituents. There are number of such examples where the plant such as turmeric known to possess $\mathrm{Ca}^{++}$antagonist activity but no clinical use in cardiovascular disorders, probably due to the presence of vasoconstrictor constituents (Gilani et al., 2005).

The present investigation on $R$. coriaria clearly demonstrated its antisecretory, antidiarrheal and antispasmodic activities possibly mediated through $\mathrm{Ca}^{++}$antagonist pathway, thus, providing a sound mechanistic background to validate its indigenous use in hyperkinetic gut disorders.

\section{Acknowledgements}

The study was conducted with partial financial support from Higher Education Commission, Government of Pakistan. We would like acknowledge the contribution Prof. Altaf Ahmad Dasti, a taxonomist at the Institute of Pure and Applied Biology, Bahauddin Zakariya University, Multan for his assistance in identification of the plant material used in this study.

\section{References}

Abbas SMN, Halkman AK. Antimicrobial effect of water extract of sumac (Rhus coriaria L.) on the growth of some food borne bacteria including pathogens. Int $\mathrm{J}$ Food Microbiol. 2004; 97: 63-69.

Bolton TB. Mechanism of action of transmitters and other substances on smooth muscles. Physiol Rev. 1979; 59: 606718.

Brading AF. How do drugs initiate contractions in smooth muscles? Trend Pharmacol Sci. 1981; 2: 261-65.

Candan F, Sokmen A. Effects of Rhus coriaria L. (Anacardiaceae) on lipidperoxidation and free radical scavenging activity. Phytother Res. 2004; 18: 84-86.

Candan F. Effect of Rhus coriaria L. (Anacardiaceae) on superoxide radical scavenging and xanthine oxidase activity. J Enzyme Inh Med Chem. 2003; 18: 59-62.

Chakraborty A, Ferk F, Simic T, Branter A, Dusinská M, Kundi M, Hoelzl C, Nersesyan A, Knasmüller S. DNA-protective effects of Sumach (Rhus coriaria L.), a common spice: results of human and animal studies. Mut Res. 2009; 661: 10-17.

Croci T, Landi M, Elmonds-Alt X, Le Fur G, Maffrand JP, Manara L. Role of tachykinins in castor oil-induced diarrhea in rats. Br J Pharmacol. 1997; 121: 375-80.

Duke JA, Bogenschutz-Godwin MJ, Du Celliar J, Duke PAK. Rhus coriaria L. In: Handbook of medicinal herbs. $2^{\text {nd }}$ ed, Boca Raton, CRC Press, 2002.

Farre AJ, Columbo M, Fort M, Gutierrez B. Differential effects of various $\mathrm{Ca}^{++}$antagonists. Gen Pharmacol. 1991; 22: 17781.

Giancarlo S, Rosa LM, Nadjafi F, Francesco M. Hypoglycemic activity of two spices extracts: Rhus coriaria L. and Bunium persicum Boiss. Nat Prod Res. 2006; 20: 882-86.

Gilani AH, Shah AJ, Ghayur MN, Majeed K. Pharmacological basis for the use of turmeric in gastrointestinal and respiratory disorders. Life Sci. 2005; 76: 3089-105.

Hoffman BB. Therapy of hypertension. In: Goodman and Gilman's the pharmacological basis of therapeutics. Brunton LL, Lazo JS, Parker KL (eds). 11 th ed. New York, McGraw-Hill., 2006, pp 845-68.

Iwao I, Terada Y. On the mechanism of diarrhea due to castor oil. Japanese J Pharmacol. 1962; 12: 137-45.

Janbaz KH, Shabbir A, Mehmood MH, Gilani AH. Insight into mechanism underlying the medicinal use of Cydonia oblonga in gut and airways disorders. J Anim Plant Sci. 2013; 23: 330-36.

Karaki H, Wiess G. Mini-review: Calcium release in smooth 
muscles. Life Sci. 1983; 42: 111-12.

Khan M, Shah AJ, Gilani AH. Antidiarrheal and antispasmodic activities of Vitex negundo Linn. are mediated through $\mathrm{Ca}^{++}$channel blockade. Bangladesh J Pharmacol. 2013; 8: 317-22.

Lev E, Amar Z. Ethnopharmacological survey of traditional drugs sold in the Kingdom of Jordan. J Ethnopharmacol. 2002; 82: 131-45.

Mehmood MH, Aziz N, Ghayur MN, Gilani AH. Pharmacological basis for the medicinal use of psyllium husk (ispaghula) in constipation and diarrhea. Dig Dis Sci. 2011; 56: 1460-67.

Mehmood MH, Gilani AH. Pharmacological basis for the medicinal use of black pepper and piperine in gastrointestinal disorders. J Med Food. 2010; 13: 1086-96.

Mehrdad M, Zebardast M, Abedi G, Koupaei MN, Rasouli H, Talebi M. Validated high-throughput HPLC method for the analysis of flavonolaglycones, myricetin, quercetin, and kaempferol in Rhus coriaria L. using a monolithic column. J AOAC Int. 2009; 92: 1035-45.

National Research Council. Guide for the care and use of laboratory animals. Washington, National Academy Press, 1996, pp 1-7.

Özcan M, Haciseferogullari H. A condiment [sumac (Rhus coriaria L.) Fruits]: Some physiochemical properties. J Plant Physiol. 2004; 30: 74-84.

Özcan M. Effect of Sumach (Rhus coriaria L.) extracts on the oxidative stability of peanut oil. J Med Food. 2003; 6: 63.

Reynolds IJ, Gould RJ, Snyder, SH. Loperamide: Blockade of calcium channels as a mechanism for antidiarrheal effects. J Pharmacol. 1984; 231: 628-32.
Seidler, NW, Jona I, Vegh M, Martonosi A. Cyclopiazonic acid is a specific inhibitor of the $\mathrm{Ca}^{++}$-ATPase of sarcoplasmic reticulum. J Biol Chem. 1989; 264: 17816-23.

Shabbir A. Rhus coriaria Linn., A plant of medicinal, nutritional and industrial importance: A review. J Anim Plant Sci. 2012; 22: 505-12.

Shah AJ, Zaidi MA, Sajjad M, Hamidullah, Gilani AH. Antidiarrheal and antispasmodic activities of Vincetoxicum stocksii are mediated through calcium channel blockade. Bangladesh J Pharmacol. 2011; 6: 46-50.

Shah AJ, Begum S, Hassan SI, Ali SN, Siddiqui BS, Gilani AH. Pharmacological basis for the medicinal use of Psidium guajava leave in hyperactive gut disorders. Bangladesh J Pharmacol. 2011A; 6: 100-06.

Shah N, Shah AJ, Ahmed M, Gilani AH. Functional nature of the spasmolytic effect, phytochemical composition and acute toxicity studies on Sauromatum guttatum. Bangladesh J Pharmacol. 2014; 9: 203-07.

Shanab BA, Adwan G, Safiya DA, Adwan K, Shanab MA. Antibacterial activity of Rhus coriaria L. extracts growing in Palestine. J Islamic Uni Gaza (Natural sciences series). 2005; 13: 147.

Usmanghani K, Saeed A, Alam MT. Indusyunic medicine, Karachi, University of Karachi Press, 1997, p 378.

Van Rossum JM. Cumulative concentration response curves, II. Techniques for the making of concentration-response curves in isolated organs and the evaluation of drug parameters. Arch Int Pharm Therap. 1963; 143: 299-330.

Zargham H, Zargham R. Tannin extracted from sumac inhibits vascular smooth muscle cell migration. Mcgill J Med. 2008; 11: 119-23. 